\title{
Bound Focus or How can Association with Focus be Achieved without Going Semantically Astray?*
}

\author{
Josef Bayer \\ Friedrich-Schiller-Universität Jena
}

\begin{abstract}
By the notion "bound focus", we mean phonological prominence and semantic affectedness that is dependent on the presence of a focus-demanding lexical element such as only or even. This paper tries to demonstrate that modern conceptions of syntactic theory such as the Minimalist Program explain in a natural way the various word orders that can be observed. Crucial use is made of the idea that focus particles are either base-generated in a fixed functional position or brought into this position by covert raising or by reconstruction. In deviation from the operation of feature movement ("Move-F"), arguments are provided which suggest that overt movement may indeed include the movement of phrases.
\end{abstract}

\section{Goal}

The goal of this article is to show that all cases in which a quantificational focusing particle, such as only, even and perhaps others associates semantically with a focused element in the clause, can be reduced to a canonical constellation in which the particle is the head of a "particle phrase" in which it binds the focus associate. In this case, the particle occupies an inalterable scope position. There are four cases that can be distinguished. The associative relation between particle and focus is achieved (i) directly by base-generation such that the particle is in its final scope position from where it binds its associate; (ii) by covert movement of a phrase such as only John to a position where the particle 
is able to take (clausal) scope; (iii) by reconstruction of a phrase such as only John to a position where the particle is able to take (clausal) scope; (iv) by reconstruction of the focus associate to a position where the particle can bind it. The treatment, which makes crucial use of the theoretical machinery developed in the Minimalist Program (Chomsky 1995) leads to a considerable reduction of the complexity that has troubled much research on bound focus in the past. It can especially be shown that intuitions about phrase structural constituency can rather easily be reconciled with the desired semantics of focusing particles. Although the main points can be made on the basis of English, German data will be drawn into the discussion because this language offers certain test cases that may enhance our understanding of bound focus in general.

\section{Four Types of Constructions}

I will use the category label PRT for "particle" and PrtP for "particle phrase", i.e. a functional projection that is headed by the semantically relevant functional category PRT. The intended focus associate of PRT is indicated by capitals. Consider the example in (1a) with approximately the phonetic form given. It is ambiguous between the readings connected to the different foci in (Ib) and (1c):
a. [dan wød oønlı invart meri]
b. John would [ ${ }_{\mathrm{PTP}}$ only [ ${ }_{\mathrm{VP}}$ INVITE MARY]]
c. John would [PrP only [VP invite MARY]]

In (Ib) only associates with the whole VP, while in (1c) it associates only with part of the VP. The semantics is roughly as in (2):

(2) a. For the set P of (contextually relevant) properties \{phone Susan, visit Sarah, kiss Mathilde, ..., invite-Mary\} that John would have, $\mathrm{P}$ is exhausted by invite Mary

b. For the set $\mathrm{P}$ of (contextually relevant) properties (invite (Ann), invite (Barbara), invite (Carol), ..., invite (Zeldah)\} that John would have, $\mathrm{P}$ is exhausted by invite (Mary)

Due to focus spreading, the two readings correspond to one and the same phonetic form. This is the reason for the ambiguity. PRT is a functional head which occupies a pre-VP operator position. Its complement - the VP - is a Complete Functional Complex (CFC) in the sense of Chomsky (1986). I 
assume that it contains a trace of the subject that has been moved out of VP for reasons of Case-licensing. If we follow the standard assumption that focus presupposes a set of entities against whose other members the focused element is contrasted, we achieve a split between foreground and background which determines the set that will be affected by the operator. In (lb) it is the set of all of John's contextually relevant properties, while in (lc) it is the set of all of John's contextually relevant properties of inviting someone. Thus, the focused element corresponds to a variable. Simplifying matters somewhat, only according to Rooth (1985) translates into $\lambda P \lambda x[\forall Q[[Q\{x\}] \rightarrow Q=P]]$. (lb,c) are readily converted to LFs that can be semantically interpreted: If $P$ corresponds to the entire VP, the semantic translation that is yielded is $[\forall Q[[Q\{J o h n\}] \rightarrow Q=$ invite Mary]]; if $P$ corresponds to the VP [invite $y$ ], the semantic translation that is yielded is $[\forall \mathrm{Q}, \mathrm{Q}=$ invite y $[[\mathrm{Q}\{\mathrm{John}\}] \rightarrow \mathrm{Q}=$ invite Mary $]]$. This provides the core cases, where the LF is essentially read off the syntactic string directly.

Consider now the following example where this is clearly not possible:

$$
\text { John would invite [? only [DP MARY]] }
$$

If only is part of DP - something like a "modifier" of DP, it cannot head PrtP. PRT does not c-command anything like a CFC in this case. Thus, it is prima facie unclear how PRT can have propositional scope. Nevertheless, the meaning of (3) appears to be more or less the same as the meaning of (1c). Assume now that PRT is not evaluated in situ but rather undergoes covert raising to the standard operator position. In this case, there are two options: Either PRT itself moves to the head position of PrtP from where it can bind the focused element Mary, or the entire phrase only Mary moves to the specifier of PrtP (SpecPrtP) whose head it "identifies". In the latter case, the carried-along focused element Mary has to be reconstructed into its original position. In each of these cases, an LF is created that can be interpreted as outlined above in connection with (1c).

Before we move on to a more thorough investigation of this constellation, let us look at yet two other possibilities. Consider first the situation in which PRT is part of a DP as in (3), but where this DP is higher in the phrase marker than the purported pre-VP head position. In English, this situation holds whenever PRT is part of a DP in SpecIP; in German, whenever PRT is part of a DP (or any other phrase) in SpecCP:
a. [? only [DP MARY]] would invite us to her home
b. [? nur [DP MARIA]] würde uns nach Hause einladen 
If PrtP were headed as in ( $\mathrm{lb}, \mathrm{c})$, these examples would not conform to the standard pattern, because in that case PRT should be able to associate also with material that is lower in the phrase marker. As Jackendoff (1972) has already observed and as shown by (5), this is impossible though:
a. *Only Mary would invite US to her home $/{ }^{*} \ldots$ to her HOME
b. *Nur Maria würde UNS nach Hause einladen $/ * \ldots$ nach HAUSE einladen

This seems to be clear indication that PRT and DP form a single constituent in (5), and that PRT is not in a proper scope position yet. The situation in German is even clearer. Due to the VERB-SECOND (V2) CONSTRAINT, the position in front of würde in (5b) must be a single constituent. In this case, it is expected that nur is part of the DP in SpecCP and will not c-command anything but Maria. Notice now that if PrtP is as in $(1 \mathrm{~b}, \mathrm{c})$, only Mary/nur Maria has to undergo lowering in such a way that it fills SpecPrtP and identifies the head of PrtP. Then, the focus associate Mary has to be lowered further to SpecVP. In this case it can be bound by PRT which is now in proper scope position. As will be shown below, this situation is naturally accounted for in the Minimalist framework.

Consider finally a situation where PRT does occupy the propositional scope position, but where its focus associate has been raised higher such that it cannot be bound by PRT. With respect to the particle only, modern English shows a restriction here which had been noticed at least as early as Jackendoff (1972), but which seems to have been absent in earlier stages of the language. This is shown in (6):

(6) a. ANNA could [PrtP even / ?* only [ ${ }_{\mathrm{VP}}$ escape from the prison]]

b. The eldest son shall only inherit his father (18th century)

(Taglicht 1984: 97, n35)

While in (6a) the focused phrase Anna can easily associate with even, for many speakers association with only seems to be much harder or totally impossible. As the example in (6b) shows, however, this must be a more recent development of the English language. The only analysis of $(6 \mathrm{~b})$ that achieves a natural interpretation is such that only associates with eldest. ${ }^{1}$ The German example from Primus (1992) in (7) shows that there is no restriction on nur as compared to sogar (and other particles) in modern German.

(7) ANNA entkam ${ }_{1}\left[\right.$ PrtP $_{\text {S }}$ sogar/nur [ ${ }_{\mathrm{VP}}$ dem Gefängnis $\left.\left.\mathrm{e}_{1}\right]\right]$ Anna escaped even/only the-DAT prison 
Perhaps the reason lies in the fact that earlier stages of English and German have the V2-property while modern English has only residues of V2. ${ }^{2}$ If we ignore the problem with English only, the situation seems to be clear enough though: PRT is in situ, and the associate that has been raised to a higher position must be lowered to a position where it can be bound by PRT. Then, the only difference between (6)/(7) and (4) is that in the former PRT overtly occupies the propositional scope position in PrtP while in the latter it has to somehow reconstruct into this position.

This concludes my overview of the four situations in which PRT can bind associated focus material: (i) PRT is the head of PrtP and binds a focus in its ccommand domain; (ii) PRT and some XP form a constituent, and either PRT must undergo covert raising to a proper scope position, or [PR'T XP] move together to SpecPrtP covertly; (iii) [PRT XP] is "too high" in the phrase marker for PRT to be in a proper scope position, and must therefore be reconstructed into a lower position; (iv) PRT is in proper scope position while its focus associate is "too high"; thus, the associate must reconstruct into a lower position where it can be bound by PRT. I take (i) to be representative of the situation in which PRT occupies its ultimate scope position and c-commands its focus associate. The interpretation of bound focus is straightforward in this case as has been shown by Rooth (1985), Kratzer (1991) and others. I take it that at the level of LF the other constructions can be interpreted analogously because they all involve an abstract syntactic structure which reflects this elementary configuration.

\section{Characteristics of bound focus}

In this section, I want to discuss characteristics of bound focus, some of which may be novel in research on this phenomenon.

\subsection{PRT requires a focus constituent}

PRT always requires a focus associate. As the examples in (8) and (9) show, if it cannot bind any focus associate, PRT is not licensed:

(8) a. Sally likes only HIM / *it

b. Sabine liebt nur IHN / *es

(9) a. Sally likes even HIM $/ *$ it

b. Sabine liebt sogar IHN / *es 
The pronoun him is stressed, but since it and es are notoriously unstressed, the sentences become deviant as soon as these weak or clitic pronouns are used. This property of bound focus follows from the semantics of PRT. PRT always requires a non-trivial set such that there is an ALTERNATIVE to the focused element. Such an alternative exists, for example, for full pronouns on different dimensions (gender: $\{h e$, she $\}$, person $\{I$, you, ... $\}$, deixis: $\{$ this, that $\}$, etc.), but not for clitics etc. ${ }^{3}$ With respect to only, Tancredi (1990) proposes the PRINCIPLE of LeXical Association (PLA): ${ }^{4}$

(10) Principle of Lexical association

An operator like only must be associated with a lexical constituent in its c-command domain.

The PLA accounts for the '?*' in (6a), but it is a lexical stipulation that does not capture the data on foci which may be bound by even. It would also fail to account for (6b) and for (7). Despite my present ignorance concerning the restrictions on only in modern English, I would favor the following generalized version of the PLA:

(11) Principle of Lexical Association (ReVISED)

At LF PRT must be associated with a lexical constituent $\mathrm{L}_{\mathrm{m}}$ or a trace of $\mathrm{L}_{\mathrm{m}}$ in its c-command domain such that $\mathrm{L}_{\mathrm{m}}$ is a member of the set $\left\{\mathrm{L}_{1}, \mathrm{~L}_{2}, \ldots, \mathrm{L}_{\mathrm{n}}\right\}$ where every $\mathrm{L}_{\mathrm{m}-1}$ is a discourse alternative to $\mathrm{L}_{\mathrm{m}}$.

Since (11) requires association only at the level of LF, it fails to capture the restriction on only. If some lexical constituent $\mathrm{L}$ is related to the c-command domain of PRT by a trace, this trace - which I will argue is an LF-COPY of L - can be bound by PRT. In making a statement about the whole class of PRTs, (11) is, of course, more general than (10). It is also more explanatory because it makes a statement as to what "associate" means. As the discussion of only in section 2 has shown, its meaning requires a non-trivial set of alternatives. As far as I can see, this is also true for the additive particles even, also, too and a number of elements such as at least, at most etc. as well as for most of those German particles that have been studied extensively by Altmann (1976; 1978).

\subsection{PRT attaches only to a potential $X^{\max }$}

Strings such as those in (12) and (13) give the impression that PRT may attach to any category that satisfies the revised version of PLA in (11). 
(12) a. Some students smoke even IN the classroom

b. Only LITTLE boys are permitted to use the ladies' restroom

(13) a. Einige Studenten rauchen sogar IN dem Hörsaal

b. Nur KLEINE Buben dürfen die Damentoilette benutzen

Since in English even and in German both sogar and nur can optionally be postposed, it is easy to test this impression. As (14) and (15) show, it is wrong:

(14) *Some students smoke [IN even] the classroom

(15) a. *Einige Studenten rauchen [IN sogar] dem Hörsaal

b. *[KLEINE nur] Buben dürfen die Damentoilette benutzen

A necessary though not always sufficient condition is that PRT is postposed behind the smallest $\mathrm{X}^{\mathrm{max}}$ that contains its focus associate. This yields grammatical results.

(16) Some students smoke [[IN the classroom] even]

(17) a. Einige Studenten rauchen [[IN dem Hörsaal] sogar]

b. [[KLEINE Buben] nur] dürfen die Damentoilette benutzen

This suggests that PRT is a head that takes an XP as its complement. Additional data from German at first sight seem to contradict this generalization. In (18), nur seems to form a constituent with the category $\mathrm{V}^{0}$ :

a. Peter hat das Buch nur DURCHGEBLÄTTERT

Peter has the book only skimmed-through

b. Nur DURCHGEBLÄTTERT hat Peter das Buch

As den Besten and Webelhuth (1987), Müller (1998) and others have shown, however, there is an analysis that does not force us to the conclusion that nur attaches to $\mathrm{V}^{0}$ here. German has the option of scrambling material out of VP. Thus, in (18) PRT may well be attached to VP, but this VP contains a scrambling trace of the direct object instead of the lexical object itself. This analysis is sketched in (19):

(19) a. ... das Buch B $_{i}$ [nur [vP $t_{i}$ durchgeblättert]]

b. [nur [VP $t_{i}$ durchgeblättert]] ... das Buch $_{i}$

I conclude that PRT is indeed a head that follows X-bar theory closely enough to permit only an XP-complement. We will shortly turn to the question of how from structures like [PRT [... FOCUS ...]] or [[... FOCUS ...] PRT] a standard 
interpretation can be derived which has PRT in proper (propositional) scope position from where it can bind the focus associate.

\subsection{PRT is a "minor" functional head}

In which sense is PRT a regular syntactic (lexical or functional) head? Notice that functional heads usually select only one type of complement: C selects IP, I selects VP, D selects NP to mention the most popular cases. ${ }^{5}$ Looking at the list in (20), we must conclude instead that PRT is totally promiscuous:
a. only Bill
nur Willi
DP
b. only to London
nur nach London
PP
c. only poor
nur arm
AP
d. only go to London
nur nach London fahren
VP
e. only that he goes to London nur daß er nach London fährt CP

School grammar classifies particles as ADVERBS. Categorial grammar in the Montague tradition introduced them like other functional elements such as negation as SYNCATEGOREMATIC expressions. ${ }^{6}$ Both traditions are right in the sense that particles are non-inflecting minor categories, that they MODIFY their target rather than determine it, and that they nevertheless make an important contribution to semantic composition. But how should PRT fit into more restrictive versions of X-bar theory? As I have already done in Bayer (1996: ch.1), I want to follow a suggestion by Rothstein (1991) who introduces the category MINOR FUNCTIONAL HEAD (MFH). MFHs are heads which lack a $\theta$-grid, and which do not project categorial features. Thus, if an MFH takes XP as a complement, the resulting category will nevertheless be of syntactic type XP. This achieves exactly what syncategorematic introduction in Montague grammar achieves, but now on the basis of a deficient matrix of syntactic features such that PRT becomes amenable to the parsimonious principles of phrase structure composition. Following Rothstein, I assume for the cases in (20) the phrase structure representations $\left[_{\mathrm{DP}}\right.$ only $\left[_{\mathrm{DP}}\right.$ Bill $\left.]\right],{ }_{\mathrm{PP}}$ only $\left[_{\mathrm{PP}}\right.$ to London] $], \ldots,\left[_{\mathrm{CP}}\right.$ only [CP that he goes to London]]. Is this in conflict with our earlier assumption of a phrase PrtP? It is not, if we recognize that PrtP is essentially a SEMANTICALlY defined category. The difference between PrtP and, say, only Bill is that in the former but not in the latter PRT is in an operator position. ${ }^{7}$ The generalization in (21) tries to capture this state of affairs. ${ }^{8}$ 
(21) PRT being a MinOR FunCtional Head cannot project syntactic categorial features unless it occupies an operator position; in this case, PRT heads the functionally defined phrase PRTP.

The semantics of PRT is such that it cannot be evaluated without a restrictive phrase and a scope in the sense of Heim (1982). This makes it comparable to standard quantificational expressions like every student. In (3), which I repeat now with the proper phrase structure in (22),

(22) [IP John [I' would [VP invite [DP only [DP MARY]]]]]

Mary is the restrictive part and the CFC corresponding to the open proposition $\lambda x$ invite (John, $x$ ) is the scope. Given the PRINCIPLE of FULL INTER PRETATION (Chomsky, 1986: 98ff; 1995), only would count as an uninterpreted item at LF and therefore cause derivational crash, if it could not reach a scope position. In Bayer (1996), I discuss a host of cases which show that derivations involving PRT crash exactly where no syntactically licit derivation can be found in which [PRT XP] moves to a virtual scope position. No such obstacle is present in (22). Thus, there is a possible derivation in abstract syntax as shown in (23) where [PRT XP] has moved to SpecPrtP:

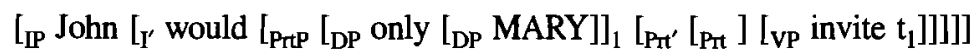

According to standard assumptions (see Rizzi, 1990; 1991), there is an agreement relation between Spec and the head. Thus, features present in SpecPrtP appear also in the related abstract head position. If this is true, we are entitled to rewrite (23) as (24):

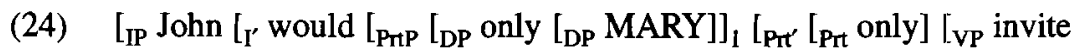
$\left.\left.\left.\left.\left.t_{1}\right]\right]\right]\right]\right]$

If the trace is an LF-copy of the moved phrase, and if PRT is an operator that is licensed in propositional scope position, then we can apply Chomsky's (1995) copying-and-deletion mechanism by which the restrictive phrase - here the focus associate - is deleted in the operator position, while it appears as a copy in the position of the trace. Since PRT now occupies the head of PrtP, PRT can be deleted in SpecPrtP as well. This leads to the LF-representation in (25).

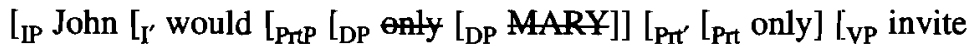
[DP lDP MARY]]]]]]] 
(25) is semantically equivalent to the base-generated structure in (1c) and can be straightforwardly connected with a standard semantic interpretation as in Rooth (1985). ${ }^{9}$ This gives a sufficiently clear picture of the analysis of examples such as (3).

\subsection{Association with focus is not focus movement toward PRT}

The theory of bound focus outlined so far assumes sentences of type (1) as basic in the sense that they can be interpreted more or less directly, while sentences of type (3) require abstract movement. This view is not shared by everybody, and it seems to me that some syntacticians still adhere to the idea that PRT must associate with a focus constituent by a process of movement. We know that sentences with PRT in operator position may have a reading that is indistinguishable from the meaning of sentences in which PRT is a co-constituent of some $\mathrm{XP}$. The long-lived idea is that in a case like (1c), John would $\left[_{\mathrm{PrT}}\right.$ only [VP $_{\mathrm{VP}}$ invite MARY]], where Mary is the sole carrier of focus, the focus associate moves to PRT. It has, however, been observed as early as Anderson (1972) that such movement would violate all sorts of syntactic constraints. Consider the following:

(26) a. *Who do you dislike [the idea [that $\mathrm{t}_{1}$ is tall for a Watusi]]?

b. John even has [the idea [that $\mathrm{HE}$ is tall for a Watusi]]

While overt movement of who in (26a) would violate both the EMPTY CATEGORY PRINCIPLE (ECP) and the COMPLEX-NP-CONSTRAINT (CNPC), focus association with even in (26b) does not seem to violate any such constraint. Discrepancies of this kind have often led to major complications of the organization of grammar. LF was said to be less restrictive than S-structure. ${ }^{10}$ In the face of the sharp grammaticality contrast in (26), it seems preferable to conclude that the focus does not move to PRT at all. Notice in addition to this, that a single PRT may bind more than one focus. "In English and German it is, however, not possible to move different phrases overtly to one and the same target position. Consider now the following English and German examples of multiple focus binding:

(27) a. I have only suggested that DOMINGO should sing "Tristan" in VIENNA (but not that PAVAROTTI should sing it in SALZBURG)

b. Ich habe nur vorgeschlagen, daB DOMINGO den "Tristan" in WIEN singen sollte (aber nicht $\mathrm{daB}$ PAVAROTTI ihn in SALZBURG singen sollte) 
Domingo and Vienna are not part of any simplex constituent that could undergo movement to only. The focus-movement analysis then forces us to recursive adjunction to SpecPrtP, an operation that may be permitted, but for which there is hardly any evidence in English and German. Taken together, the problems connected with (26) and (27) suggest that there is no focus movement to PRT at all, and that in both cases PRT has propositional scope over a CFC which is an appropriate semantic objeçt for association with focus. A set of discourse alternatives as required by (11) is easily invoked. For (26b) it would be thave the idea that he is tall for a Watusi, have the idea that she is tall for a Watusi, have the idea that that one is tall for a Watusi, ...); for (27a) it would be (suggest that Domingo should sing "Tristan" in Vienna, suggest that Pavarotti should sing "Tristan" in Salzburg, suggest that Kollo should sing "Tristan" in Berlin, suggest that Aschenbach should sing "Tristan" in Weimar, ... . Since according to the present theory PRT is in canonical operator position and binds at least one focus such that this focus invokes a set of alternatives, there is no reason whatsoever to move the focus toward PRT. In this case, no island is violated, and multiple movement into a single XP-position is not required.

A desirable side effect of this result is that we can derive the fact that once PRT is in scope position its scope is fixed, whereas a scope position has to be targeted in case PRT heads a non-scopal XP. To take an example, (26b) means something else than John has [the idea [that even HE is tall for a Watusi]]. The scope of even is confined to the IP in which it occurs. As can be expected from the effect of the ECP and the CNPC, (covert) raising of [PRT XP] to the matrix clause is out of the question. Given the well-formedness of $(26 \mathrm{~b})$ and $(27 \mathrm{a}, \mathrm{b})$, however, the conclusion must be that as long as PRT c-commands a focus, this focus may be arbitrarily far away. ${ }^{12}$

This account also provides a way to deal to deal with those examples in which PRT is a MFH of a constituent which properly contains the focus. As examples (12) through (17) have shown, PRT can associate in [PRT XP] with any subpart of XP as long as this subpart corresponds to a variable that ranges over a non-trivial set as specified in (11). Take example (12a) - Some students smoke even IN the classroom. The previous discussion has made it clear that PRT does not form a constituent with P. Thus, the proper syntactic structure must be (28):

(28) Some students smoke $\left[_{\mathrm{PP}}\right.$ even [PP $\mathrm{IN}$ [DP $_{\mathrm{DP}}$ the classroom]]] 
The procedure of assigning PRT to a propositional scope position from where it can bind the focused $\mathrm{P}$ is the same as in (22). The only difference here is that for reasons of syntactic constituency more than the focus associate must be raised to SpecPrtP. After raising, head identification and deletion, the LF of (28) will be as in (29):

(29) Some students $\left[_{P_{T t P}}\left[_{P P}\left[_{P P} \mathbb{N}\left[_{D P}\right.\right.\right.\right.$ the smoke $\left[_{\mathrm{PP}}\right.$ [ $\left[_{\mathrm{PP}} \mathrm{IN}\right.$ [DP the classroom] ]]1]]

The relevant set for this LF is \{smoke in the classroom, smoke in front of the classroom, ... $\}$. Given the standard semantics of even developed by Karttunen and Peters (1979), interpretation is again straightforward. Notice, however, that under the assumption that nothing but PRT must be raised for semantic reasons, (25) and (29) are instances of LF-Pied-Piping. I will turn to this aspect of my analysis in Section 6.

\section{Lowering}

We can so far account for two manifestations of bound focus: (i) Base-generation of PRT as the head of PrtP such that PRT c-commands a focus associate; (ii) movement of [PRT XP] to SpecPrtP such that the head of the virtual phrase PrtP is identified. Consider now those cases in which either PRT is higher than its purported canonical scope position, or the focus associate is higher than PRT. Relevant examples appeared in (4) - Only Mary would invite us to her home and in (6) - ANNA could even/?*only escape from the prison - respectively.

Turning first to (4), we notice that PRT and its focus associate form a single phrase, and that this phrase is in a non-operator surface position. For proper semantic evaluation, it has to undergo reconstruction such that PRT ends up in a head position. A solution is readily achieved, if we follow the proposal that the subject is generated as a specifier of the verb which then moves to SpecIP for Case reasons. ${ }^{13}$ According to the minimalist implementation of trace theory, [PRT DP] exists after Spell-Out as a copy in SpecVP. Let us imagine now that the copy can undergo LF-movement to SpecPrtP. This presupposes the following representation at Spell-Out:

(30) Only MARY would [VP [ 
The PF-deleted part would then undergo LF-raising to the hypothesized pre-VP position and activate PRT in the required operator position. Although this would yield the desired LF, we must be suspicious. The reason is that the derivation amounts to the raising of a trace, an operation that has explicitly been banned for reasons I cannot go into here. ${ }^{14}$ Let us therefore pursue a different solution. Assume that the phrase only Mary has not moved to SpecIP directly but rather that it has first moved through SpecPrtP. In this case, there is a copy in SpecPrtP which could activate the head PRT in operator position. Then the actual representation of (4) is not as in (30) but as in (31a); given that the filled Specposition can abstractly activate the head position of PrtP, and deletion applies according to the principles of the LF-side of the grammar, the relevant parts of the LF of (4) would be as in (31b):

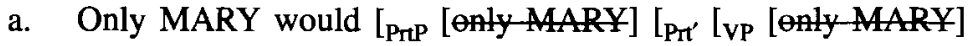 invite us to her home]]]
(PRE SPELL-OUT)
b. Only MARY would [PrP [enly MARY] [Prt only [vP [enly MARY] invite us to her home]]]
(POST SPELL-OUT)

The above-mentioned problem in connection with the raising of trace dissolves. Of course, the question remains whether movement to SpecIP requires access of the intermediate SpecPrtP-position. I will give an argument in favor of this solution directly which is not fully conclusive but nevertheless suggestive.

Let us now turn to the last type of bound focus, namely to the constellation in which PRT binds a focus that is not c-commanded but rather c-commands PRT itself. This situation is exemplified in (6) - ANNA could even/?*only escape from the prison. The proper minimalist description of this case is, of course, that the focus associate has been raised to a higher position, and that this movement has left a copy behind which at LF serves as the bindee required by the version of PLA given in (11). The question is from which position the focus associate raises. There are two options: Either it raises from a DP such as even $A N N A$, or it raises from a position which is already bound by PRT in its final operator position. It is easy to see that only the second option is available. Consider the examples in (32):

(32) a. SALLY I guess $t_{1}$ was even arrested $t_{1}$

b. *SALLY 1 I guess $t_{1}$ was arrested $\left[_{D P}\right.$ even $\left.t_{1}\right]$

c. ${ }^{*}$ SALLY $_{1} I$ guess $\left[\right.$ DP even $\left.t_{1}\right]$ was arrested $t_{1}$ 
These data show that PRT is in its ultimate scope position when the focus associate undergoes raising. It cannot be the case that the focus leaves a DP of which PRT is an MFH as would be expected if a DP of type [DP1 PRT DP2] were initially generated from which the focus phrase DP2 is moved to SpecIP and then to SpecCP. I will refrain from a discussion of movement from DP, but it seems plausible that such movement could only occur under very special circumstances. ${ }^{15}$ Given the facts displayed in (32), it can be assumed that there is also a PrtP in (4) although its head is only abstractly represented. I take this as, at least, indirect support for my suggestion that topicalizations of this sort have abstractly activated SpecPrtP. The proper LF-representations of (6) and (32a) would then be as in (33a) and (33b) respectively:

\footnotetext{
a. ANA could $\left[_{\mathrm{PIP}}\right.$ even $[\mathrm{VP}$ [NNA] escape from the prison]]

b. SALLY I guess SALLY was [PrP even [VP arrested SALLY]]
}

If tenable, this shows that all the word order variation that is observed in connection with bound focus can be reduced to a single format - a format that satisfies the revised PLA.

\section{A Bare Phrase Structure Implementation}

In the Minimalist Program of linguistic theory as envisaged in Chomsky (1995), $\mathrm{X}$-bar syntax is abandoned in favor of the basic operations MERGE and MOVE. Merge is reduced to the combination of lexical and categorial features. Move is split up into essentially two different operations that correspond to the derivations before and after Spell-Out. If Move applies before Spell-Out, the process is subject to generalized Pied-Piping; if it applies after Spell-Out, it is reduced to the movement of features (MovE-F). Features are not categories. The movement of categories is, thus, triggered by restrictions on morphophonological convergence. According to the minimalist philosophy, it is to be avoided, unless it is necessitated by morphophonological output constraints.

How should the syntax and semantics of bound focus be implemented in this framework? Assume that for an example like (1c) — John would only invite $M A R Y$ - the VP is formed according to the theory of bare phrase structure. The item invite and the item MARY are merged. Since the verb turns out to be a head that requires an argument, the resulting category is a projection of this head. The 
result is formally \{invite, \{invite, MARY\}\}. Merge can then be applied to only and the structure which may now be called "VP". This yields fonly, \{only, VP\}\}. According to (21), PRT does not have a syntactic category unless it occupies an operator position. In \{only, \{only, VP\}\}, only is able to take scope over VP, a CFC. Thus, \{only, \{only, VP\}\} amounts to \{PRT, \{PRT, VP\}\}. In this structure, PRT can bind either the entire VP or a focus associate that is a proper part of VP.

Consider now the example only Mary as it appears in (3). The bare phrase structure is $\{$ only, $\{$ only, DP $\}$, but now PRT cannot project syntactic categorial features. For only to be licensed, it has to move to a position where it is. According to the theory developed in Chomsky (1995: ch.4), covert movement cannot be movement of the entire phrase. It must be movement of the relevant quantificational features of PRT. ${ }^{16}$ This would derive the proper LF of examples such as (3). Consider now (6) - ANNA could even/?*only escape from the prison. As we have shown, PRT occupies a scope position here. Then the focus associate must have been raised higher because of some feature that needs to be checked before Spell-Out. The exact nature of this feature is not relevant here. Assume it to be [top]. Since movement has left a copy of the focus associate behind, this copy will be bound by PRT. Consider finally the examples in (4) Only Mary would invite us to her home and its German equivalent which is a V2-clause. Given the plausible assumption that at LF PRT must occupy a scope position from which it binds a focus associate, how can the Move-F theory deal with this case? There are two options: (i) Instead of raising, the features of PRT will undergo LOWERING. (ii) PRT raises from the LF-copy that the phrase only Mary has left behind. Option (i) should be disfavored for the simple reason that lowering operations have mostly proved to be either untenable or unnecessary. Option (ii) seems to conflict at first sight with the verdict against the raising of trace. At closer inspection, however, one can see that it does not amount to the raising of the trace/copy but rather to the raising of a suB-label of the trace/copy.

My sketch seems to lead to a minimalist implementation of focus association in the sense of Chomsky's proposal that Move-F is to be preferred over Move- $\alpha$ as long as output constraints remain unaffected. The rest of this article deals with a set of problems which nevertheless emerge from Move-F, and which can be avoided under the more conventional theory of covert Move- $\alpha$. 


\section{The Derivation of Wide Scope for PRT}

Let us ask the question whether the scope of PRT can be determined by Move-F where $\mathrm{F}$ is the semantically relevant feature of PRT. In the following, I will draw attention to some problems that are likely to be solved more straightforwardly by covert Move- $\alpha$ than by Move-F.

\subsection{Minimal Links}

According to Chomsky (1995: 271), raising of a pure feature $\mathrm{F}$ is adjunction of $F$ to a head which projects. $F$ is supposed to make the shortest possible move. Any violation of the MINIMAL LINK CONDITION (MLC) is said to be illegitimate (p. 267f). It has been found, however, that the scope of PRT is not necessarily local in the sense that PRT takes the closest possible domain as the scope domain. Taglicht (1984) has observed sentences in which only may, under certain circumstances, take scope wider than the clause in which it appears overtly. This can be seen in the following examples:

(34) a. The students in the GDR were required to learn only RUSSIAN

b. The GDR education ministry demanded that the students learn only RUSSIAN

(34a) can mean that the GDR students were required to learn no other language than Russian. This is factually false because it means that it was forbidden for students in the GDR to study foreign languages such as Chinese, English or Spanish. (Mind control was not that rigid after all!) (34a) has another reading, however, which is factually true. It means that of all foreign languages, Russian was compulsory. Nothing is said as to the freedom to learn Chinese, English, Spanish etc. The same kind of ambiguity arises in (34b) where we find a finite complement. The more "realistic" reading can be achieved if only takes scope in the matrix clause rather than in the clause where it arises. But this move is not readily compatible with the MLC.

\subsection{Attraction by [prt-]?}

To make it compatible, we are forced to hypothesize a silent affixal feature that attracts the semantic feature corresponding to PRT. Let us call the affixal feature for the sake of the example [PRT-]; [prt-] may enter the numeration at different 
stages of the derivation. For the false reading where only remains in the scope of require, [prt-] is an affix to the verb learn; for the true reading where require is in the scope of only, [prt-] is an affix to the verb require. So far so good. The problem with this solution is that the attractor [prt-] is a device which adds too much power to the system of UG. What is the evidence for this conclusion? Consider the German versions of (34) given in (35):

(35) a. Die Studenten in der DDR wurden gezwungen nur RUSSISCH zu lernen

b. Das Bildungsministerium der DDR verlangte, daß die Studenten nur RUSSISCH lernten

These sentences are not ambiguous at all. They permit only the false interpretation, i.e. nur takes narrow scope. This is unexpected because the true reading is readily achieved, if nur is overtly inserted in the matrix clause:

(36) a. Die Studenten in der DDR wurden nur gezwungen RUSSISCH zu lernen

b. Das Bildungsministerium der DDR verlangte nur, daß die Studenten RUSSISCH lernten

Before I continue discussing this effect, a caveat is necessary to which my attention has been drawn by Büring and Hartmann (1996). We know from the work of Taglicht and Rooth that the scope of PRT is fixed as soon as PRT is in the pre-VP operator position. The English sentence The students in the GDR were required to only learn RUSSIAN ceases to be ambiguous. Büring and Hartmann are right in arguing that this might be the only analysis for sentences like (35). The head-final nature of the German VP does not allow us to see unambiguous constituency. Thus, given the fact that an operator does not undergo raising from an operator position, it would not be surprising that the scope of nur cannot be extended into the matrix clause. Recall, however, that in German nur can also be postposed. ${ }^{17}$ In that case, it must form a constituent with the preceding focus associate. The only plausible syntactic structure would be [DP $_{\mathrm{DP}}$ RUSSISCH] nur]. The question is now whether the examples in (34) turn out to be ambiguous if we change them as in (37):

(37) a. Die Studenten in der DDR wurden gezwungen [RUSSISCH nur] zu lernen

b. Das Bildungsministerium der DDR verlangte, da $ß$ die Studenten [RUSSISCH nur] lernten 
They remain unambiguous. This is unexpected, if [prt-] could have been inserted in the matrix clause, as it must be assumed for English according to the theory of pure feature movement. I conclude from this and a host of further evidence which I cannot include here that "semantic attractors" such as [prt-] are not allowed in any derivation. The alternative is that, where semantically necessary, PRT must raise "by itself". This throws us back to the question why there is this difference in LF scope options between English and German. ${ }^{18}$ As far as I can see, the theory of pure feature movement does not give an answer.

\subsection{Island Constraints}

Assume alternatively that it is not the pure feature corresponding to PRT that undergoes covert movement, but rather the entire phrase. This phrase can target whatever landing site is there to fulfill the needs of PRT. According to our assumptions, its primary semantic need is to take sentential scope. This can be achieved in the lower or in the higher clause. As long as a syntactic derivation in terms of successive cyclicity is available, it is a matter of free choice which scope is taken. The empirical consequence is, of course, that we predict island effects. The following examples show that island constraints are active.

(38) a. The GDR education ministry made the suggestion to learn only RUSSIAN

b. The GDR education ministry made the suggestion that the students learn only RUSSIAN

(39) a. The conformist student asked the ministry [where to study [only RUSSIAN]]

b. The conformist student asked the ministry [where he could study [only RUSSIAN]]

All of these sentences are unambiguous. They permit only a narrow scope interpretation of PRT. This shows that at least the CNPC and the wh-IsLANDConstraINT must be active, contrary to the popular idea that LF-derivations are not constrained by subjacency. The question is what blocks transclausal scope of PRT in German. An answer was given in Bayer (1996) in terms of the typological difference that sets the SOV-language German aside from the SVOlanguage English. ${ }^{19}$ According to the theory developed there, scoping out of complements which appear on the non-canonical, right side of $\mathrm{V}$ is only possible if the matrix clause hosts an OVERT operator. In English and other VO-languages 
where the complement is on the canonical side of $\mathrm{V}$, covert wide scope can be achieved, if there is a possible derivation which respects subjacency. The activity of island constraints as shown in (38) and (39) suggests that it is SpecCP that must be accessible. This implies that the covert operation is Move- $\alpha$. For Move$\mathrm{F}$ it is said instead that "the computation 'looks at' only $\mathrm{F}$ and a sublabel of [the target of movement, J.B.] K". In this case, it should not matter how deeply F is embedded in the phrase in which it occurs. ${ }^{20}$ This cannot be appropriate for those cases, however, in which PRT has to be assigned sentential scope. I would like to mention only two examples. Consider first German PPs. German does not allow P-stranding. Thus, PP should be an island for the covert extraction of a DP that is headed by PRT, but not for a feature that corresponds to PRT. The data in (40) address this point:

(40) a. Sie haben nur an ANNA gedacht the have only at Anna thought 'They thought only about Anna'

b. *Sie haben an nur ANNA gedacht

Despite the fact that nur can form a constituent with DP, nur+DP is bad inside PP. This is not expected if PRT can raise as an abstract feature. It is expected, however, if the primary step in the LF-derivation is covert movement of the phrase nur ANNA. Consider next an example from English. As has been shown by (16) - Some students smoke [[IN the classroom] even] — English permits postposed even. If the assignment of scope to even is not affected by the degree of embedding in, say, a DP, we would not expect the following difference:

(41) a. [[ANNA's father] even] was arrested

b. *[[ANNA even]'s father] was arrested

The feature corresponding to PRT should extract from the complex DP in (41b), but contrary to this prediction it does not. If we assume, however, that it is the entire phrase ANNA even that has to undergo movement, embeddedness matters. (41b) is, in this case, ruled out as a violation of the LEFT-BRANCH-CONSTRAINT (LBC). The question remains, of course, how the occurrence of Wh in the same environments is licensed:

(42) a. Wer hat [an wen] gedacht? who has at whom thought

'Who has thought about whom?'

b. [Who's father] was arrested? 
I cannot try to give an answer here, but it is not obvious that it should be sought under the assumptions of the theory of pure feature movement. If we try to do so, we must draw a distinction between different types of operator features and explain why some respect islands and others don't. ${ }^{21}$

\subsection{A morphological reflex of movement}

Let me finally point to another property of sentences which allow a wide scope interpretation of PRT. As has been pointed out by Longobardi (1991: 187, note 8) and Richard Kayne (p.c.), neither Italian nor English seem to allow the relevant wide scope interpretation, if the finite complement which hosts PRT happens to be in the indicative mood. Thus, (43) - as opposed to (34b) would not permit the wide scope interpretation:

(43) The GDR education ministry demanded that Michael learns only RUSSIAN

Similarly, the Italian examples of transclausal scope of solo, soltanto or solamente which are adduced in Longobardi (1991) always show finite complements in the subjunctive mood.

(44) a. E' veramente necessario che io parl -i soltanto con Gianni is really necessary that I speak -SUBJ only with Gianni

b. E' davvero indispensabile che lui cred -a che io is truly indispensable that he believe -suBJ that I desider-i vedere soltanto Gianni wish-SUBJ see only Gianni Longobardi (1991:153)

(44a) is ambiguous between an interpretation of soltanto in the embedded clause or in the matrix clause. (44b) is three-way ambiguous with soltanto taking scope in either of the three clauses.

In his discussion of differences between overt and covert movement, Chomsky (1995: 267) ascribes the presence of a morphological reflex of this kind to successive-cyclic $w h$-movement. The fact that such a reflex is a precondition of wide scope interpretation of PRT could then lead to two different conclusions. Either there is indeed overt movement of some kind of zero operator as Watanabe (1992) has argued, or covert movement is largely the same as overt movement, i.e. it is Move-a and not Move-F. Since I see no evidence for overt movement of a silent operator in the syntax of PRT-scope, I tend to keep to the 
older theory according to which UG has the option of moving syntactic categories covertly. ${ }^{22}$

\subsection{A solution without Move-F}

It was shown in Section 5 that by and large the minimalist conception of grammar offers important insights into the syntax of bound focus. It should not be overlooked, however, that the adoption of the subtheory of pure feature movement ("Move-F") leads to predictions and expectations which are hardly compatible with the scope facts that are revealed by the grammar of PRT.

Since Move-F is nothing like the movement of categories, it remains to be seen whether it has properties that are distinct from those of Move- $\alpha$. The conceptual question that remains is how desirable a theory of grammar is in which LF and PF are "maximally different", as suggested by this theory. ${ }^{23}$ For the time being, I would rather stick to the theory of abstract Spec-head agreement that underlies the analyses presented in Section 3 and 4 . If we do so, we can show how the different interpretations of ambiguous examples like (34a) The students in the GDR were required to learn only RUSSIAN - can be derived. Assume that the semantics of PRT forces it to move to a position where it can be interpreted unless PRT occupies a proper scope position before SpellOut. Since only, being part of the DP only RUSSIAN, does not occupy such a position, the phrase must undergo movement. This movement is under the control of syntactic constraints on movement. The first landing site that this DP can target is the VP in which it occurs. Let DP adjoin to VP. Does this move create an interpretable semantic object? It clearly does not. The adjoined DP cannot be evaluated according to the semantics we have adopted from Rooth (1985). The process of adjunction can, however, be seen somewhat differently. Assume that DP has moved to the specifier of a VIRTUAL phrase PrtP that comes into existence by agreement with the specifier. In terms of bare phrase structure, nothing is required but the usual assumption that the target projects. If the target VP projects according to the semantic features associated with PRT, the result will be an abstractly represented PrtP. The rest is straightforward. The DP only RUSSIAN has "identified" the head of the virtual PrtP. Since its trace is a copy of the original, deletion can now apply and reduce the structure in such a way that the final result is a structure with PRT in head position that binds its focus associate in the "reconstructed" position. The result appears in (45). Its interpretation derives the meaning according to which it was required that apart from Russian no other language could be learned. 
(45) The students in the GDR were required [IP PRO to [PrtP [enly RUSSIAN] [[Prt only] [vp learn [enly RUSSIAN]]]]]

According to the actual world, (45) achieves the truth-value 0 . How is the wide scope reading derived? If PRT were attracted by the minimal scope domain that can satisfy its semantic needs, and if the feature PRT would undergo checking, no ambiguity could be expected. Notice, however, that according to the present proposal PRT is neither attracted nor checked. If the semantics of PRT can be evaluated in an arbitrary position that can satisfy its scopal needs, and if this position can be targeted without any violation of movement constraints, the ambiguity is predicted. Imagine that indicative mood corresponds to a feature which arises in I and is copied onto $\mathrm{C}$, and that it erects a barrier that is absent if the mood feature chosen is subjunctive. In this case, the DP only RUSSIAN may move successive-cyclically through SpecCP to the matrix-VP which is headed by the verb require. The resulting structure is given in (46).

(46) The students in the GDR were [PTP [enly-RUSSIAN] [ [ ${ }_{P_{11}}$ only] [ [VP required [ ${ }_{\mathrm{CP}}$ RUSSIAN [IP $_{\mathrm{IP}}$ PRO to [ [ SIAN]]]]]]]

(46) represents the wide scope reading of PRT. According to the actual world, it achieves the truth-value 1 . The question may arise as to why the grammar of English does not allow overt transclausal movement of this sort. Notice, however, that it does not even allow intra-clausal movement to SpecPrtP. We can stick to the minimalist conjecture that the Procrastinate principle rules out overt derivations that can equally well be achieved covertly.

\section{Conclusion}

The syntax and semantics of bound focus has been an enormous challenge to linguistic theory. Much useful semantic work has been done in the past which has set standards which had to be met by syntactic analysis. Unfortunately, the syntactic side of these accounts was often sketchy and less illuminating. It seems to me that the minimalist theory of grammar has opened up interesting possibilities of bridging the gap between syntax and semantics that has always been visible in this domain as well as in a number of related phenomena such as negation. ${ }^{24}$ The reason for this lies in what I see as the greatest virtue of this theory, namely the strictly uniform treatment of overt and covert operations in 
grammar. The only point where my account of bound focus diverges from the theory as outlined in Chapter 4 of Chomsky (1995) concerns the sub-theory of pure feature movement, which was rejected, and this is exactly the point where overt and covert operations diverge from each other.

\section{Notes}

* I want to thank the audience of the Table ronde internationale sur la grammaire du focus where this material was presented, especially Michael Brody, Nomi Erteschik-Shir and Laurie Tuller. Special thanks to Noam Chomsky, who was kind enough to respond with a detailed letter to my questions concerning feature movement.

1. Nomi Erteschik-Shir (p.c.) suspects that the discrepancy between only and even in modern English has something to do with the fact that the former but not the latter is an eliminative operator. See also Erteschik-Shir (forthcoming: ch.3). I cannot exclude the possibility that dialectal and stylistic factors play a role as well. Laurie Tuller (p.c.) informs me that for her postposed only is in fact possible, and that such constructions occur regularly in poetry and song. See also note 2 .

2. Thanks to Nomi Erteschik-Shir for suggesting this possibility. The difference between only and even can also be seen in phrases like even Mary and Mary even where both orders are possible, while with respect to only the order *Mary only is excluded. Although in German the order Maria nur is somewhat stilted, it is not ungrammatical. In the last act of Richard Wagner's "Parsifal" we hear

(i) die Wunde schlieBt der Speer nur, der sie schlug the wound closes the spear only that it cut

'Only the spear that caused the wound may close it again'

At the moment I have nothing to say about the stylistic factors that are affiliated with postposed nur/only.

3. That the phenomenon is independent of focusing particles is shown by topicalization data from German. As Travis (1984) has observed, a clitic (or weak pronoun) es cannot be topicalized.

(i) ${ }^{*} \mathrm{Es}_{\mathrm{i}}$ hat der Hund $\mathrm{t}_{\mathrm{i}}$ gefressen

it has the dog eaten

Likewise, separable prepositional prefixes to verbs can only be topicalized if the prefixed verb $\mathrm{P}-\mathrm{V}$ has a lexical alternative $\mathrm{P}^{\prime}-\mathrm{V}$ in which the meaning of $\mathrm{V}$ remains constant. Thus, there is the pair auf-machen ('open') zu-machen ('close'), but there is no alternative to the prefix verb auf-hören ('stop') or ab-liefern ('deliver'). If topicalization requires a non-trivial set of alternatives, the following contrasts are explained:

(ii) a. $\mathrm{AUF}_{\mathrm{i}}$ hat er die Tür $\mathrm{t}_{\mathrm{i}}$ gemacht (und nicht $\mathrm{ZU}$ )

open has he the door made and not closed

'He OPENED the door (but did not CLOSE it)' 


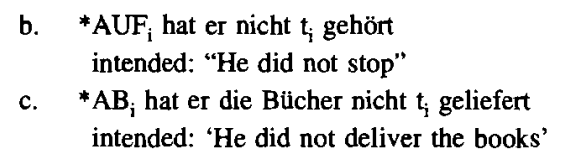

4. See also Aoun and $\mathrm{Li}$ (1993) for discussion.

5. See van Riemsdijk (1996) for the role of functional heads in the extension of lexical projections.

6. See Karttunen and Peters (1979) and Jacobs (1983).

7. For reasons of space, I leave out one complicating aspect: The eliminative particle only can also operate on sets that are hierarchically ordered, i.e. on so-called SCALES. Consider the following examples:

(i) a. The scientist found the dangerous substance in only three organisms

b. Some only weakly gifted students applied for the job

(ii) a. Der nur mit einer Badehose bekleidete Gangster konnte entfliehen the only with a swim-suit dressed gangster could escape

b. Der Journalist hat die Mütter von nur zehn Jugendlichen befragt the journalist has the mothers of only ten teenagers interviewed

In none of these examples is it the case that only/nur takes scope over more than the respective scales "number of organisms", "degree of giftedness", "amount/value of garment", "number of teenagers"; only/nur is in an operator position here, but it does not have propositional scope. See Bayer (1996) for extensive discussion.

8. The same seems to hold for the relation between term negation and sentential negation. I assume that (ii) involves a NegP, while (i) is a negative statement only on a more abstract level of semantic interpretation.

(i) Not John, but Fred, was here

(ii) John was not here, but Fred (was)

9. While Rooth also considers treatments in terms of type raising, this is not necessary here because in the present system [PRT XP] phrases reduced to the standard case by LF-movement.

10. See Huang (1981) and much work that took up the conclusion that LF is not controlled by subjacency.

11. This has been denied by Tancredi (1990), who proposed that apparent cases are to be derived by V-raising from a focused VP; as I have pointed out in Bayer (1996), however, there are other cases which cannot be captured in this way. Thus the assumption of multiple bound foci is unavoidable.

12. See also Kratzer (1991) and Bayer (1996) for further discussion. I want to thank Michael Brody for a controversial discussion of this point.

13. See Sportiche (1988), Koopman and Sportiche (1991) among many others.

14. See Chomsky (1995: 304) where the following is proposed:

(i) Trace is immobile

(ii) Only the head of a chain $\mathrm{CH}$ enters into the operation Attract/Move

Thanks to Peter Suchsland for discussion of this point. 
15. I think of the NP/DP-split phenomenon that is likely to hold in cases of "floated quantifiers" and similar constructions where DP or NP appears to have left a more complex phrase that is headed by a quantifier or some other material. Although much insightful work has been devoted to this area over the years, the linguistic descriptions remain controversial.

16. Chomsky is very brief about similar cases, but nevertheless explicit. See Chomsky (1995: 337) where a feature [quant] is assumed that raises to a potential host. The target of movement in Chomsky's proposal $\mathrm{T}$ or $\mathrm{v}$ - can have an affixal feature [quant-] which may be chosen in a numeration or not.

17. Examples like (17b) - [[KLEINE Buben] nur] dürfen die Damentoilette benutzen - are to my ears completely natural. See also (i) from note 2 .

18. Ortiz de Urbina (this volume) reports that in Basque neither Wh nor focus may undergo abstract movement from the (extraposed) complement to the matrix clause, while, according to Tsimpli (1995), focus in Greek seems to have matrix scope, even if the focus phrase appears in the complement. According to the theory developed in Bayer (1996), this result is expected because Basque has a head-final VP; thus a clausal complement to the right of $\mathrm{V}$ appears in noncanonical position. Greek has a head-initial VP; thus a clausal complement to the right of $\mathrm{V}$ appears in canonical position. See also my remarks in 6.3 .

19. For reasons of space, I cannot repeat my argumentation here. The reader is referred to Bayer (1996).

20. See Chomsky (1995: 269) where the example Pictures of whose mother did you think were on the mantelpieces is adduced to show that the wh-feature can be deeply embedded in the DP. As we know from other languages, however, this is the exception rather than the rule.

21. A first attempt has been made in Longobardi (1991) and in Bayer (1996: 113ff), and further developed in Bayer (1995; 1998).

22. Independent evidence in favor of the same conclusion has been given in Wilder (1997). See also Guéron and May (1984) and subsequent work which shows that certain LF operations must involve Pied-Piping in order to void Principle $C$ effects. Compare (i) and (ii):

(i) ${ }^{*}$ I told her $r_{\mathrm{j}}$ that the concert was attended by many people last year who made the soprano $\mathrm{i}_{\mathrm{i}}$ quite nervous

(ii) I told her $r_{i}$ that the concert was attended by so many people last year that the soprano became quite nervous.

Raising of so or its features is not sufficient. We can undo Principle C only if the entire phrase whitch contains the soprano leaves the c-command domain of her.

23. This question was raised in Brody (1996). While the expectable reaction would be to switch back to the classical LF-theory in which LF and PF are maximally similar by virtue of the fact that both involve movements of genuine syntactic entities, Noam Chomsky (p.c.) would draw a different conclusion. He pursues the idea that overt movement is also Move-F, and that all checking takes place within extended lexical items. Successive-cyclic overt movement would then be Move-F, followed by pied-piping. In this case, the purported differences between overt and covert movement would equally have to vanish. See Chomsky (1998) for an elaboration of this idea.

24. See Moritz and Valois (1994) for an interesting account which is very much in the spirit of what I had to say about PRT. 


\section{References}

Altmann, Hans. 1976. Die Gradpartikeln im Deutschen. Untersuchungen zu ihrer Syntax, Semantik und Pragmatik. Tübingen: Niemeyer.

Altmann, Hans. 1978. Gradpartikel-Probleme. Zur Beschreibung von gerade, genau, eben, ausgerechnet, vor allem, insbesondere, zumindest, wenigstens. Tübingen: Narr.

Anderson, Stephen. 1972. "How to get even," Language 48.893-906.

Aoun, Joseph, and Yen-hui Audrey Li. 1993. "wh-elements in situ: syntax or LF?". Linguistic Inquiry 24.199-238.

Bayer, Josef. 1995. "Quantification, agreement and Pied-Piping". Talk presented at the Hungarian Academy of Science, Budapest, 03.10.95.

Bayer, Josef. 1996. Directionality and Logical Form: On the Scope of Focussing Particles and wh-in-situ. Dordrecht: Kluwer.

Bayer, Josef. 1998. "Two types of covert movement." Talk presented at the workshop on Acquisition and Variation in Syntax and Semantics, SISSAL, Trieste, 3.-6.9.98.

Besten, Hans den and Gert Webelhuth. 1987. "Remnant topicalization and the constituent structure of VP in the Germanic SOV-languages," GLOW Newsletter 18.15-16. (Talk presented at the 1987 GLOW-conference, Venice).

Brody, Michael. 1996. "Focus in perfect syntax". Talk presented at the Table ronde internationale sur 1a grammaire du focus, Paris 22.-23.February 1996.

Büring, Daniel, and Katharina Hartmann. 1996. "Bemerkungen zur Syntax und Semantik einiger fokussensitiver Partikeln im Deutschen unter besonderer Berücksichtigung sententialer Komplementation". Talk presented at the GGS meeting, Berlin.

Chomsky, Noam. 1986. Knowledge of Language: Its Nature, Origin and Use. New York: Praeger.

Chomsky, Noam. 1995. The Minimalist Program. Cambridge, Massachusetts: MIT Press.

Chomsky, Noam. 1998. "Minimalist Inquiries: the Framework." MIT Occasional Papers in Liguistics: 15.

Erteschik-Shir, Naomi. Forthcoming. The Dynamics of Focus Structure. Ms. Ben Gurion University, Beer Sheva.

Guéron, Jaqueline and Robert May. 1984. "Extraposition and Logical Form". Linguistic Inquiry 15.1-31. 
Heim, Irene. 1982. Semantics of Definite and Indefinite Noun Phrases. Ph.D. dissertation, University of Massachusetts, Amherst.

Huang, C.-T. James. 1982. Logical Relations in Chinese and the Theory of Grammar. Ph.D. dissertation, MIT.

Jackendoff, Ray. 1972. Semantic Interpretation in Generative Grammar. Cambridge, Mass.: MIT Press.

Jacobs, Joachim. 1983. Fokus und Skalen: Zur Syntax und Semantik der Gradpartikeln im Deutschen. Tübingen: Niemeyer.

Karttunen, Lauri, and Stanley Peters. 1979. "Conventional implicature". In: Choon-Kyu $\mathrm{Oh}$ and David A. Dinneen (eds.) Presupposition, Syntax and Semantics, vol. 11. New York: Academic Press.

Koopman, Hilda and Dominique Sportiche. 1991. "The position of subjects". Lingua 85.211-258.

Kratzer, Angelika. 1991. "The representation of focus,". In: Stechow, Arnim von and Dieter Wunderlich (eds.), Semantics: An International Handbook of Contemporary Research. Berlin: de Gruyter.

Longobardi, Giuseppe. 1991. "In defense of the correspondence hypothesis: island effects and parasitic constructions in Logical Form." In C.-T. James Huang and Robert May (eds.), Logical Structure and Linguistic Structure. Dordrecht: Kluwer.

Moritz, Luc, and Daniel Valois. 1994. "Pied-piping and specifier-head agreement". Linguistic Inquiry 25.667-707.

Müller, Gereon. 1998. Incomplete Category Fronting. A Derivational Approach to Remnant Movement in German. Dordrecht: Kluwer.

Ortiz de Urbina, Jon. This volume. "Focus in Basque".

Primus, Beatrice. 1992. "Selbst - variants of a scalar adverb in German". In Joachim Jacobs (ed.): 1992. Informationsstruktur und Grammatik. Linguistische Berichte, Sonderheft 4. Opladen: Westdeutscher Verlag.

Riemsdijk, Henk van. 1996. "The extension of projections". Ms. Tilburg University/CLS. (To appear in the Tsuru University Papers in Linguistics.)

Rizzi, Luigi. 1990. Relativized Minimality. Cambridge, Mass.: MIT Press.

Rizzi, Luigi. 1991. "Residual verb second and the wh-criterion". Technical Reports in Formal and Computational Linguistics 2. University of Geneva.

Rooth, Mats 1985. Association with Focus. Ph.D. dissertation, University of Massachusetts, Amherst. 
Rothstein, Susan 1991. "Heads, projections, and category determination". In: Katherine Leffel and Denis Bouchard (eds.), Views on Phrase Structure. Dordrecht: Kluwer.

Sportiche, Dominique. 1988. "A theory of floating quantifiers and its corollaries for constituent structure". Linguistic Inquiry 19.425-449.

Taglicht, Joseph 1984. Message and Emphasis: On Focus and Scope in English. London: Longman.

Tancredi, Christopher. 1990. "Not only even but even only". Ms., MIT.

Travis, Lisa. 1984. Parameters and Effects of Word Order Variation. Ph.D. dissertation, MIT Cambridge, Massachusetts.

Tsimpli, Ianthi 1995. "Focussing in modern Greek". In: Katalin É. Kiss (ed.), Discourse Configurational Languages. Oxford: Oxford University Press.

Watanabe, Akira. 1992. "WH-in-situ, subjacency and chain formation". MIT Occasional Papers in Linguistics 2.

Wilder, Chris. 1997. "Phrasal movement in LF". Talk presented at the International Conference on Pied-Piping, Jena 29-31 May 1997. 